\title{
Bone histomorphometry and structure in corticosteroid treated chronic active hepatitis
}

\author{
A J STELlON, A WEBB, AND J E COMPSTON \\ From the Liver Unit, King's College Hospital, London, and \\ The Department of Histopathology, St Thomas' Hospital, London
}

SUMmary Transiliac biopsies from 34 female patients with corticosteroid treated chronic active hepatitis have been examined to determine the contributions made by decreased bone formation and increased bone resorption to bone loss associated with this condition and to determine the structural basis of the bone loss. Mean wall thickness was significantly reduced when compared with control values $(p<0.001)$ as was the bone formation rate at tissue $(p<0.005)$ and basic multicellular unit $(p<0.005)$ level. The osteoid maturation period and the bone formation period were significantly prolonged $(p<0.02$ and 0.05$)$. The total resorption surfaces were significantly increased $(p<0.02)$ but the mean interstitial bone thickness was normal. The mean trabecular plate thickness was significantly reduced $(p<0.005)$. These findings indicate that decreased bone formation plays a major role in bone loss associated with corticosteroid treated chronic active hepatitis and that the structural basis of bone loss is trabecular thinning.

Reduced trabecular and cortical bone mass have recently been reported in patients with autoimmune chronic active hepatitis (CAH) on maintenance corticosteroids. ${ }^{2}$ Corticosteroids are known to induce bone loss, probably as a result both of direct inhibition of bone formation and an increase in parathyroid hormone mediated bone resorption secondary to calcium malabsorption; ${ }^{--8}$ non-steroid treated chronic liver disease is also associated with an increased prevalence of osteoporosis. ${ }^{9-13}$ Detailed bone histomorphometric studies in patients with chronic cholestatic or alcoholic liver disease have shown that reduced bone formation plays a major role in bone loss, although increased resorption may also contribute; ${ }^{13-16}$ in addition, the mechanism of bone loss in chronic cholestatic liver disease at the microanatomic level appears to be trabecular thinning rather than erosion through and removal of whole trabecular elements. ${ }^{\text {is }}$ The pathophysiology of bone loss associated with steroid treated $\mathrm{CAH}$ has

Address for correspondence: Dr J E Compston, Department of Pathology, University of Wales College of Medicine, Cardiff, CF4 4XN.

Received for publication 24 September 1987. not been reported. In this study we have examined the changes in bone histomorphometry and microanatomic structure in iliac crest biopsies from 34 female patients with $\mathrm{CAH}$ receiving longterm corticosteroid therapy.

Methods

PATIENTS

The 34 female patients, aged $20-66$ years (19 postmenopausal), fulfilled internationally agreed criteria for autoimmune CAH. ${ }^{17}$ Twenty two of the 34 patients had biopsy proven cirrhosis, documented in one or more biopsies, over a period of one to 12 years. At the time of study all patients were in biochemical and histological remission as defined by a serum aspartate transaminase (SGOT) level of less than $40 \mathrm{IU} / \mathrm{l}$ and a liver biopsy appearance of chronic persistent hepatitis or an inactive cirrhosis without piecemeal necrosis. All patients had received prednisolone for a minimum period of one year (median 3.6 years; range $1-12$ ) and were maintained on doses of $5 \mathrm{mg} /$ day in two patients, $7.5 \mathrm{mg} /$ day $(8), 10 \mathrm{mg} /$ day (23), and $12.5 \mathrm{mg} /$ day (1). Thirty one patients in addition were receiving azathioprine $50-100 \mathrm{mg} /$ day . 
Table 1 Clinical details of patients and controls

\begin{tabular}{|c|c|c|c|}
\hline & $\begin{array}{l}\text { Controls } \\
\text { (30) }\end{array}$ & $\begin{array}{l}\text { Chronic active } \\
\text { hepatitis } \\
\text { (34) }\end{array}$ & $p$ Value \\
\hline Age & $46 \cdot 7(14 \cdot 9)$ & $45(15 \cdot 6)$ & NS \\
\hline Pre-/postmenopausal & $15 / 15$ & $15 / 19$ & \\
\hline Years since menopause & $11 \cdot 6(9 \cdot 2)$ & $7 \cdot 4(4 \cdot 6)$ & NS \\
\hline
\end{tabular}

Results are expressed as mean (SD).

Two patients were on thyroxine replacement therapy for myxoedema and thyroid function tests at the time of study were normal. No patient had received previous vitamin $\mathrm{D}$ or calcium supplementation and no patient had clinical evidence of steatorrhoea. Informed consent was obtained in all patients and the study was approved by the local Ethical Committee.

Three patients at the time of study suffered lower lumbar back pain and one patient generalised aches in all her limbs. Two patients had sustained fractures (wrist one, and humerus one) before corticosteroid therapy and lateral radiographs of the thoracolumbar spine had revealed one patient with a wedged vertebra.

Control data were obtained from 30 healthy women ( 15 postmenopausal) aged $20-69$ years, with no biochemical or radiological evidence of metabolic bone disease, who underwent an iliac crest biopsy at the same time as a minor surgical procedure was being carried out under general anaesthetic. ${ }^{18}$ The controls were comparable with the patients with respect to mean age and years since menopause (Table 1). Quantitative analysis of both the $\mathrm{CAH}$ and healthy control biopsies was carried out by one of us (AS) to exclude interobserver variation. Sections were coded so that the observer was unaware of whether they had been obtained from control or patient biopsies.

\section{BIOCHEMISTRY}

Serum concentrations of calcium, alkaline phosphatase, albumin and urinary calcium and creatinine concentrations were measured by standard methods. Serum calcium concentrations were corrected for the serum albumin concentration. ${ }^{19}$ Serum 25 -hydroxyvitamin D concentrations were measured by a competitive protein binding assay after extraction and chromatography. Serum immunoreactive parathyroid hormone (iPTH) levels were measured by an $\mathrm{N}$-terminal immunoradiometric assay using an antibody raised in sheep to synthetic 1-34 PTH peptide. ${ }^{20}$

\section{BONE HISTOLOGY}

Full thickness transiliac biopsies were obtained, with a modified Bordier trephine of $8 \mathrm{~mm}$ internal dia- meter, $2 \mathrm{~cm}$ below and behind the anterior superior iliac spine. Two contiguous specimens were obtained whenever possible and were fixed in $10 \%$ phosphate buffered formalin ( $\mathrm{pH} 7$ ) and embedded in methylmethacrylate. Non-consecutive $8 \mu \mathrm{m}$ sections were cut with a Jung $\mathrm{K}$ microtome and stained with haematoxylin and eosin (H\&E), solochrome cyanin $\mathrm{R}$ or by the von Kossa technique using a van Giesen counterstain; $15 \mu \mathrm{m}$ unstained sections were also prepared for fluorescence microscopy.

All volumes were measured by point counting and all surfaces quantified using a Zeiss integrating eyepiece, containing 25 points and 5 parallel lines. The distance between two fluorescent labels and all thickness measurements were made using an eyepiece micrometer. One division on the eyepiece graticule was equivalent to $1.40 \mu \mathrm{m}$ at $400 \times$ magnification.

The following static parameters were quantified:

Total trabecular bone volume (TBV; \%)

The total trabecular bone volume, mineralised and unmineralised, expressed as a percentage of the total medullary volume including bone and marrow spaces. A minimum of 100 fields from four or more von Kossa stained sections were examined at $100 \times$ magnification.

\section{Relative osteoid surface (OS; \%)}

The percentage of total trabecular bone surface covered by osteoid. A minimum of 100 fields or four or more von Kossa stained sections were examined at $100 \times$ magnification.

Specific surface of trabecular bone $\left(\mathrm{S}_{\mathrm{v}} ; \mathrm{mm}^{2} / \mathrm{mm}^{3}\right)$ The number of square millimetres of trabecular bone surface lying in a typical cubic millimetre of whole trabecular bone tissue. ${ }^{21}$

Surface to volume ratio $\left(\mathrm{S} / \mathrm{V} ; \mathrm{mm}^{2} / \mathrm{mm}^{3}\right)$

This is the amount of trabecular surface existing on the typical cubic millimetre of trabecular bone. ${ }^{21}$

Mean trabecular plate thickness (MTPT; $\mu \mathrm{m}$ )

This is an indirect measurement of the mean thickness of trabeculae and was derived as follows:

$$
\mathrm{MTPT}=\frac{2000^{22}}{\mathrm{~S} / \mathrm{V}}
$$

Mean trabecular plate separation (MTPS; $\mu \mathrm{m}$ ) This is an index of the distance between trabecular plates and is calculated as follows:

$$
\text { MTPS }=\text { MTPT } \frac{100^{22}}{\text { TBV-1 }}
$$




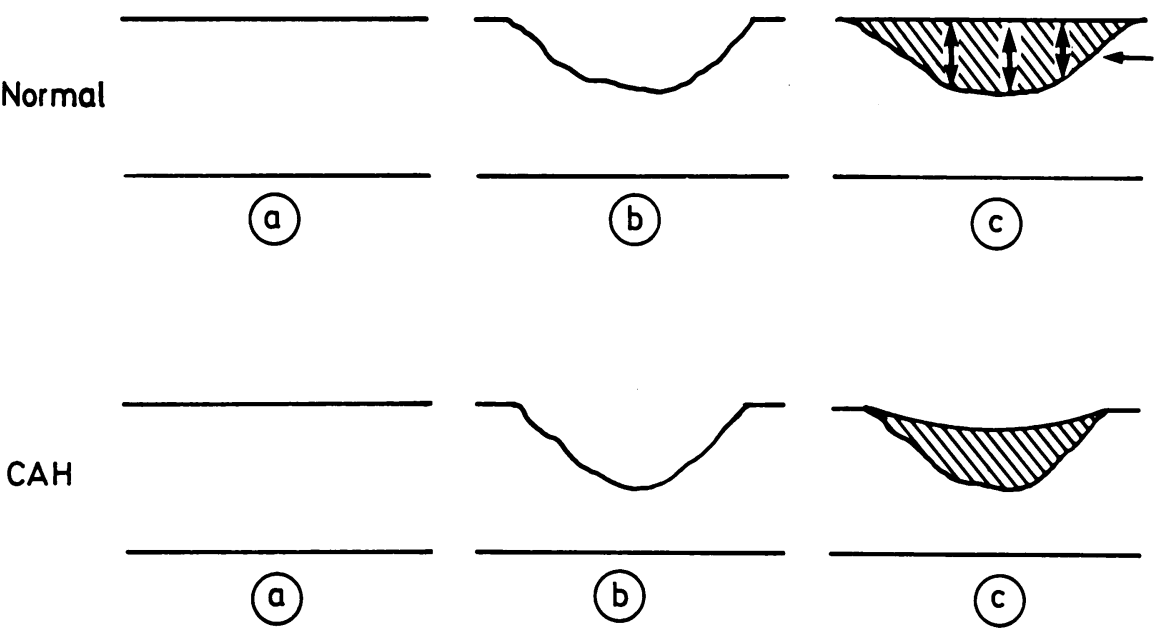

Fig. 1 Schematic representation of trabecular bone remodelling in normal steady state circumstances and in corticosteroid treated $C A H$. (a) shows a length of a trabecula of bone. Bone resorption by osteoclasts produces a resorption cavity $(b)$ along the mineralised trabecular bone surface. Bone resorption is then followed by bone formation in which the previously eroded cavity is filled in by osteoid which finally mineralises to produce bone (c). The mean thickness of the completed unit, which represents the amount of bone formed, is known as the mean wall thickness. In CAH the amount of bone resorbed is normal but the amount of bone subsequently formed is reduced leading to net bone loss at each individual bone remodelling unit.

Mean trabecular plate density (MTPD;/mm)

This provides an index of trabecular plate number and is calculated as follows:

$$
\text { MTPD }=\frac{\operatorname{TBV}(\%) \times 10^{22}}{\text { MTPT }}
$$

Cortical thickness (CT; mm)

This is the mean of the thickness of both inner and outer cortical plates. Measurements were done at 10 equidistant points along each cortical plate perpendicular to its outer surface and the mean of these values obtained.

Mean osteoid seam width (MOSW; $\mu \mathrm{m})$

This is the mean of four approximately equally spaced measurements in each osteoid covered surface in one or two von Kossa stained sections yielding a minimum of 80 readings. The osteoid seams were measured at $\times 400$ magnification.

\section{Mean wall thickness (MWT; $\mu \mathrm{m})$}

This represents the thickness of the completed bone structural unit, ${ }^{23}$ (Figs 1, 2). Measurements were made at $\times 400$ magnification under polarised light, on sections stained with solochrome cyanin R. Four equidistant measurements were made per packet and a minimum of 25 packets was measured from each biopsy from four or more sections.
Mean interstitial bone thickness (MIBT; $\mu \mathrm{m}$ )

This represents the mean thickness of the trabecular bone lying between two completed bone structural units in the trabeculae (Fig. 2) and is calculated as follows:

$$
\text { MIBT }=\text { MTPT }-(2 \times M W T)^{24}
$$

Total resorption surfaces (TRS; \%)

The percentage of total trabecular bone surface showing resorption cavities with or without osteoclasts was measured in two $\mathrm{H}$ and $\mathrm{E}$ sections under polarised light. ${ }^{25}$

\section{Dynamic parameters}

All patients received the following tetracycline labelling regimen of demeclocycline: $300 \mathrm{mg}$ bd for two days, followed after an interval of 12 days by $300 \mathrm{mg}$ bd for four days. The bone biopsy was then taken three to five days after the last dose. All fluorescence microscopy was done on unstained sections using blue light $(365 \mathrm{~nm})$.

The following parameters were measured:

Mineral appositional rate $\left(\mathrm{MAR}_{\mathrm{t}} ; \mu \mathrm{m} / \mathrm{day}\right)$

This is the mean of four equidistant measurements made along each double label in two or more sections at $400 \times$ magnification. A minimum of 60 readings 

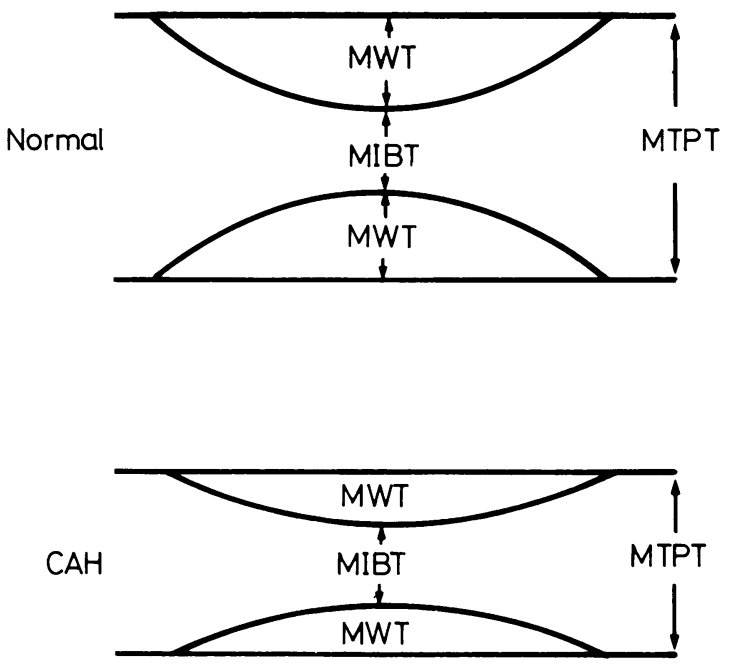

Fig. 2 Schematic diagram of part of a trabecula to illustrate the mechanism of bone loss and its effect on bone structure in corticosteroid treated $C A H$. The mean trabecular plate thickness is determined by the mean wall thickness (MWT) and the mean interstitial bone thickness (MIBT), the relationship between these three being expressed as $M T P T=(2 \times M W T)-M I B T$. The mean wall thickness represents the amount of bone formed per remodelling cycle and the mean interstitial bone thickness is indirectly proportioned to the depth of the initial resorption cavity. In corticosteroid treated $C A H$ bone formation is reduced, leading to a decreased mean wall thickness but resorption depth is normal (Fig. 1), so that the mean interstitial bone thickness is unchanged. The decrease in mean wall thickness results in a reduction in the mean trabecular plate thickness.

were obtained and the mineral appositional rate was calculated as follows:

$$
\begin{aligned}
& \underset{\text { (uncorrected }}{\text { MAR }_{t}}=\frac{\text { Mean separation between labels }}{\text { Time interval between the middle }} \\
& \text { for obliquity) of the two labelling dose regimens }
\end{aligned}
$$$$
\text { (days) }
$$

\section{Total labelled surfaces (TLS; \%)}

The length of single and double tetracycline labelled surfaces expressed as a decimal fraction of the total trabecular bone surface. These were measured on two unstained sections at a magnification of $\times 100$.

\section{Bone formation at tissue level}

(BFR (tissue); $\mu \mathrm{m}^{3} / \mu \mathrm{m}^{2} /$ day)

The amount of new bone mineralised per micrometer of trabecular bone surface area per day calculated as follows:

$$
\mathrm{BFR}(\text { tissue })=\frac{(\mathrm{DL}+\mathrm{SL})}{100} \times \mathrm{MAR}_{\mathrm{t}}{ }^{21}
$$

Bone formation at BMU level

(BFR (BMU); $\mu \mathrm{m}^{3} / \mu \mathrm{m}^{2} /$ day)

The average amount of new mineralised bone made per day per micrometer of osteoid covered surface, calculated as follows:

$$
\operatorname{BFR}(\mathrm{BMU})=\frac{\mathrm{BFR}(\text { tissue })}{\mathrm{OS} \times 10^{2}}
$$

Bone formation period ( $\sigma$; days)

The time taken for the formation of a complete bone packet, calculated as follows:

$$
\frac{\text { MWT }^{21}}{\text { BFR (BMU) }}
$$

Mineralisation lag time (MLT)

This is defined as the average lag time between apposition of collagen and initiation of mineralisation of osteoid, and is calculated as follows:

$$
\operatorname{MLT}(\text { days })=\frac{\text { MOSW }}{\text { BFR (BMU) }}
$$

STATISTICAL ANALYSIS

A two-tailed Student's $t$ test for unpaired data was carried out on all data analysed.

\section{Results}

The results of biochemical measurements are shown in Table 2. Serum calcium was decreased in two patients both of whom were premenopausal. Serum 25-hydroxyvitamin D concentrations were normal in all but three patients in whom subnormal levels (less

\begin{tabular}{|c|c|c|}
\hline & $\begin{array}{l}\text { Chronic active } \\
\text { hepatitis }\end{array}$ & $\begin{array}{l}\text { Normal } \\
\text { range }\end{array}$ \\
\hline Corrected serum calcium (mmol/l) & $2 \cdot 32(0 \cdot 08)$ & $2 \cdot 2-2 \cdot 6$ \\
\hline Serum 25-hydroxyvitamin D ( $\mathrm{nmol} / \mathrm{l})$ & $49 \cdot 9(27)$ & $12-80$ \\
\hline $\begin{array}{l}\text { Serum immunoreactive parathyroid } \\
\text { hormone }(\mathrm{pmol} / \mathrm{l})\end{array}$ & $85 \cdot 1(82 \cdot 6)$ & $<219$ \\
\hline $\begin{array}{l}\text { Fasting urinary calcium } / \text { creatinine } \\
\text { ratio }(\mathrm{mmol} / \mathrm{mol})\end{array}$ & $0 \cdot 10(0 \cdot 09)$ & $0.065(0.05)$ \\
\hline
\end{tabular}
than $12 \mathrm{~nm} /$ litre) were found. Two premenopausal patients had raised iPTH levels. The mean fasting urinary calcium creatinine ratio was not significantly different from controls despite six patients (five

Table 2 Biochemical data in patients

Results are expressed as mean (SD); Conversion from SI to traditional units; serum calcium $1 \mathrm{mmol} / \mathrm{l}=4 \mathrm{mg} / 100 \mathrm{ml}$; serum 25-hydroxyvitamin D $2.5 \mathrm{nmol} / \mathrm{l}=1 \mathrm{ng} / \mathrm{ml}$; serum immunoreactive parathyroid hormone $243 \mathrm{pmol} / \mathrm{l}=1 \mathrm{ng} / \mathrm{ml}$; fasting urinary calcium/ creatinine ratio $1 \mathrm{mmol} / \mathrm{l}$ calcium $=4 \mathrm{mg} / 100 \mathrm{ml}, 1 \mu \mathrm{mol} / \mathrm{l}$ creatine $=0.0113 \mathrm{mg} / 100 \mathrm{ml}$. 
Table 3 Static histomorphometric data in the patients and controls

\begin{tabular}{|c|c|c|c|}
\hline & $\begin{array}{l}C A H \\
(34)\end{array}$ & $\begin{array}{l}\text { Controls } \\
\text { (30) }\end{array}$ & $p$ Value \\
\hline $\begin{array}{l}\text { Total trabecular bone } \\
\text { volume }(\%)\end{array}$ & $19 \cdot 1(4 \cdot 6)$ & $23 \cdot 5(5 \cdot 8)$ & $<0.005$ \\
\hline Cortical thickness (mm) & $1.09(0.29)$ & $1 \cdot 30(0 \cdot 30)$ & $<0.005$ \\
\hline $\begin{array}{l}\text { Mean trabecular plate } \\
\text { thickness }(\mu \mathrm{m})\end{array}$ & $95 \cdot 4(19 \cdot 7)$ & $114 \cdot 5(25 \cdot 9)$ & $<0 \cdot 005$ \\
\hline $\begin{array}{l}\text { Mean trabecular plate } \\
\text { density }(/ \mathrm{mm})\end{array}$ & $2 \cdot 02(0 \cdot 32)$ & $2 \cdot 08(0 \cdot 44)$ & NS \\
\hline $\begin{array}{l}\text { Mean trabecular plate } \\
\text { separation }(\mu \mathrm{m})\end{array}$ & $414(112)$ & $390(117)$ & NS \\
\hline $\begin{array}{l}\text { Mean interstitial bone } \\
\text { thickness }(\mu \mathrm{m})\end{array}$ & $21(15 \cdot 5)$ & $21(28)$ & NS \\
\hline Osteoid surface $(\%)$ & $12 \cdot 0(8 \cdot 2)$ & $12 \cdot 3(7 \cdot 0)$ & NS \\
\hline $\begin{array}{l}\text { Mean osteoid seam width } \\
(\mu \mathrm{m})\end{array}$ & $8.41(2 \cdot 02)$ & $8.59(2.36)$ & NS \\
\hline Mean wall thickness $(\mu \mathrm{m})$ & $37 \cdot 3(6 \cdot 0)$ & $47 \cdot 0(7 \cdot 5)$ & $<0 \cdot 001$ \\
\hline $\begin{array}{l}\text { Total resorption surfaces } \\
(\%)\end{array}$ & $2.54(1.24)$ & $1.88(0.69)$ & $<0 \cdot 02$ \\
\hline
\end{tabular}

Results are expressed as mean (SD).

postmenopausal) having raised ratios of greater than $0 \cdot 16 \mathrm{mmol} / \mathrm{mol}$.

The mean trabecular bone volume was significantly lower in the $\mathrm{CAH}$ patients (Table 3 ) when compared with the control group $(\mathrm{p}<0 \cdot 005)$. Altogether $14 \%$ patients had a trabecular bone volume value within the vertebral fracture threshold range of $11(3) \%{ }^{23}$ When compared with controls a statistically significant decrease in mean trabecular plate thickness $(p<0.005)$ but not mean trabecular plate density or separation was found in the patients. No significant differences in osteoid surface, mean osteoid seam width or mean interstitial bone thickness were detected when compared with controls whereas the mean wall thickness was significantly decreased in the patients $(p<0 \cdot 001)$. Total resorption surfaces were significantly higher in the patients when compared with controls $(p<0.02)$ and $24 \%$ of patients had increased resorption surfaces $(>2 \mathrm{SD}$ above mean of age and sex-matched controls). Cortical plate thickness was decreased when compared with controls $(\mathrm{p}<0.005)$.

\section{DYNAMIC HISTOMORPHOMETRIC INDICES (Table 4)}

Calculation of the mineral appositional rate and other dynamically derived parameters were not possible in four patients because only single tetracycline labels were detectable. When compared with the controls the mineral appositional rate was significantly decreased although only one patient had a subnormal $(>2 S D)$ value. Total labelled surfaces were significantly decreased in the patients
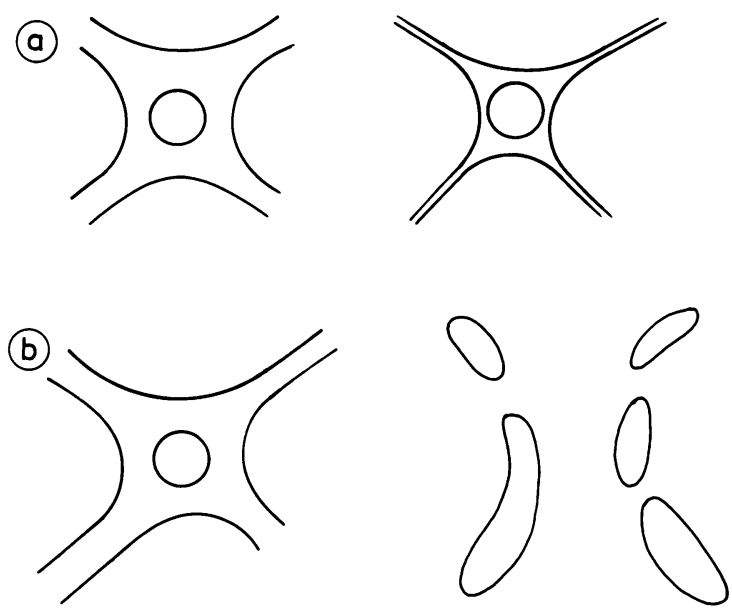

Fig. 3 Illustration of the two possible structural mechanisms of trabecular bone loss at a microanatomic level. In (a) trabecular thinning occurs, resulting in reduced bone volume with preservation of the normal trabecular architecture. In this form of bone loss, the mean trabecular plate thickness is reduced but mean trabecular plate density and separation remain unchanged. In (b), bone loss occurs by erosion through and removal of trabecular elements, leading to disruption and loss of connectivity of the normal trabecular structure. In this case the mean trabecular plate thickness is unchanged but mean trabecular plate density decreases and mean trabecular plate separation increases. In corticosteroid treated CAH mechanism (a) provides the structural basis for bone loss.

$(p<0.005)$ when compared with controls as were the bone formation rate at tissue level $(p<0.005)$ and BMU level $(p<0 \cdot 005)$. The osteoid maturation period $(p<0.02)$ and bone formation period $(p<0.05)$ were significantly prolonged when compared with the controls.

When patients were separated into those with and without cirrhosis, although age and mean daily dose of prednisolone and azathioprine were comparable in both groups, no statistically significant difference was found between the two groups with respect to any of the histological parameters measured.

Weak correlations were only found between maintenance dose of prednisolone and total resorption surfaces $(r=0.4 ; p<0.05)$ and dose duration of corticosteroid therapy and trabecular bone volume $(\mathrm{r}=-0.39 ; \mathrm{p}<0.05)$ and cortical plate thickness $(\mathrm{r}=-0.36 ; \mathrm{p}<0.05)$.

\section{Discussion}

Our results confirm previous reports ${ }^{2}$ of cortical and trabecular osteoporosis in patients with corticosteroid treated chronic active hepatitis and show 
Table 4 Dynamic histomorphometric data in the patients and controls

\begin{tabular}{llll}
\hline & $C A H$ & Controls & $p$ Value \\
\hline $\begin{array}{c}\text { Mineral appositional rate } \\
(\mu \mathrm{m} / \text { day) }\end{array}$ & $0.68(0.08)$ & $0.74(0.12)$ & $<0.05$ \\
$\begin{array}{c}\text { Total labelled surfaces }(\%) \\
\text { Bone formation rate - tissue } \\
\quad \text { level }\left(\mu \mathrm{m}^{3} / \mu \mathrm{m}^{2} / \text { day) }\right.\end{array}$ & $0.041(4.00)$ & $12.9(9.1)$ & $<0.005$ \\
$\begin{array}{c}\text { Bone formation rate - BMU } \\
\quad \text { level }\left(\mu \mathrm{m}^{3} / \mu \mathrm{m}^{2} / \text { day) }\right.\end{array}$ & $0.45(0.33)$ & $0.99(0.78)$ & $<0.005$ \\
$\begin{array}{c}\text { Bone formation period } \\
(\text { days })\end{array}$ & $129(122)$ & $70.6(43.6)$ & $<0.05$ \\
$\begin{array}{c}\text { Mineralisation lag time } \\
(\text { days })\end{array}$ & $28.9(31.0)$ & $13.7(8.4)$ & $<0.02$ \\
\hline
\end{tabular}

Results are expressed as mean (SD).

that reduced bone formation is a major contributory factor. The reduction in trabecular bone volume may have been underestimated as the decreased cortical plate thickness also observed probably resulted from endosteal resorption, creating new trabeculae which would have been included in the area for quantification of trabecular bone volume. Nevertheless, $14 \%$ of the patients studied had a value for trabecular bone volume within the vertebral fracture threshold range of $11(3) \% .^{23}$

At a microanatomic level, trabecular bone loss may be caused by either a thinning of the trabeculae, with preservation of trabecular architecture, or by erosion through and removal of trabeculae, thus reducing trabecular interconnectedness, or to a combination of both (Fig. 3). This study shows that the structural basis for bone loss in corticosteroid treated $\mathrm{CAH}$ is trabecular thinning rather than erosion through and removal of trabecular plates. Thus the mean value for mean trabecular plate thickness was significantly reduced in the patient group without any significant accompanying change in mean trabecular plate separation and density, indicating preservation of the trabecular structural pattern. This pattern of bone loss is similar to that observed in patients with primary biliary cirrhosis ${ }^{15}$ and jejunoileal bypass ${ }^{26}$ and may be associated with a lower fracture risk than bone loss involving loss of trabecular plates and reduced interconnectedness of trabeculae..$^{27}$

Mean wall thickness was significantly lower in the patient group, indicating reduced bone formation. Further evidence of low bone formation comes from the finding of a reduced bone formation rate at tissue and cellular level and the presence of only single tetracycline labelling in four patients. Although the mean osteoid seam width was normal in the patients, this, in association with a decreased mineralisation rate and prolonged osteoid maturation period indicates a reduced osteoblastic appositional rate and decreased matrix synthesis, as under conditions of normal matrix synthesis delayed mineralisation would result in an increased osteoid seam width. Because the bone formation period was increased in the patients, it seems likely that impaired function of osteoblasts rather than a reduction in lifespan was responsible for the impairment of matrix synthesis and mineralisation.

The mean total resorption surface was significantly higher in patients than in controls, although only small rises were seen. Measurement of total resorption surface, however, does not indicate resorption rate and values may be raised as a result of reduced bone formation leading to incomplete filling of normal resorption cavities. The biochemical indicators of bone resorption measured in this study, namely serum iPTH and urinary calcium/creatinine ratio were similar in patients and controls, although two patients had raised iPTH concentrations and urinary calcium creatinine ratios were increased in five patients. The most compelling evidence against a contribution by increased bone resorption to the bone loss seen comes from the measurements of mean interstitial bone thickness, which reflect the amount of bone at the BMU level which has undergone resorption in the past (Fig. 2), values for mean interstitial bone thickness in the patient group being extremely similar to those of controls. This differs from the finding that, in patients with primary biliary cirrhosis, values for mean interstitial bone thickness were significantly decreased, indicating that resorption had been increased in the past. ${ }^{15}$

The relative contributions made by liver disease and corticosteroid therapy to the bone loss seen cannot be assessed in a study of this kind. Most patients in this study were also receiving azathioprine; however, no effect of this drug on bone remodelling has been reported. The decreased bone formation and increase in total resorption surfaces observed in the present study are compatible with changes reported in corticosteroid induced bone loss in patients with normal liver function, ${ }^{35828}$ as well as in non-steroid treated patients with chronic liver disease. ${ }^{114}$ The evidence for increased activation of remodelling sites, however, reported in some studies of corticosteroid osteoporosis, with an increase not only in total resorption surface but also in osteoid surface $^{828}$ and tetracycline labelled surfaces ${ }^{28}$ was not encountered in the present study. The observation that spinal trabecular bone mineral content, measured by quantitative computed tomography is lower in patients with steroid treated $\mathrm{CAH}$ than in those with other forms of chronic liver disease ${ }^{29}$ provides indirect evidence that corticosteroid therapy may exacerbate the bone loss associated with chronic liver disease. The demonstration that bone loss associated 
with steroid treated $\mathrm{CAH}$ is predominantly a result of decreased bone formation suggests that the role of agents which increase bone formation - for example, sodium fluoride, should be evaluated in these patients.

The authors thank Advisory Services (Clinical and General), Roba Pharmaceuticals Limited and the Special Trustees, St Thomas' Hospital for general financial support. We thank Dr Roger Williams for allowing us to study his patients.

\section{References}

1 Kato, Y, Epstein O, Dick R, Sherlock S. Radiological patterns of cortical bone modelling in women with chronic liver disease. Clin Radiol 1982; 33: 313-7.

2 Stellon AJ, Davies A, Compston JE, Williams R. Bone loss in autoimmune chronic active hepatitis on maintenance corticosteroid therapy. Gastroenterology 1985; 89: 1078-83.

3 Gallagher JC, Aaron J, Horsman A, Wilkinson R, Nordin BEC. Corticosteroid osteoporosis. Clin Endocrinol 1973; 2: 355-68.

4 Hahn TJ. Corticosteroid-induced osteopenia. Arch Intern Med 1978; 138: 882-5.

5 Hahn TJ, Halstead LR, Teitelbaum SL, Hahn BH. Altered mineral metabolism in glucocorticoid-induced osteopenia. J Clin Invest 1979; 64: 655-65.

6 Adinoff AD, Hollister JR. Steroid-induced fractures and bone loss in patients with asthma. $N$ Engl $J$ Med 1983; 5: 265-8.

7 Rickers H, Deding A, Christiansen C, Rodbro P. Mineral loss in cortical and trabecular bone during high dose prednisone treatment. Calcif Tissue Int 1984; 36: 269-73.

8 Bressot C, Meunier PJ, Chapuy MC, Lejeune E, Edouard C, Darby AJ. Histomorphometric profile, pathophysiology and reversibility of corticosteroidinduced osteoporosis. Metab Bone Dis Rel Res 1979; 1: 303-11.

9 Matloff DS, Kaplan MM, Neer RM, Goldberg MJ, Bitman W, Wolfe HJ. Osteoporosis in primary biliary cirrhosis: effects of 25-hydroxy-vitamin $\mathrm{D}_{3}$ treatment. Gastroenterology 1982; 83: 97-102.

10 Herlong HF, Recker RR, Maddrey WC. Bone disease in primary biliary cirrhosis: histologic features and response to 25-hydroxyvitamin D. Gastroenterology 1982; 83: 103-8.

11 Stellon AJ, Davies A, Compston JE, Williams R. Osteoporosis in cholestatic liver disease. $Q J$ Med 1985; 57: 783-90.

12 Hodgson SF, Dickson ER, Wahner HW, Johnson KA, Mann KG, Riggs BL. Bone loss and reduced osteoblast function in primary biliary cirrhosis. Ann Intern Med 1985; 103: 855-60.

13 Bikle DD, Genant HK, Cann C, Recker RR, Halloran BP, Strewler GJ. Bone disease in alcohol abuse. Ann Intern Med 1985; 103: 42-8.

14 Cuthbert JA, Pak CYC, Zerwekh JE, Glass KD,
Coombes B. Bone disease in primary biliary cirrhosis: increased bone resorption and turnover in the absence of osteoporosis or osteomalacia. Hepatology 1984; 4: $1-8$.

15 Stellon AJ, Webb A, Compston JE, Williams R. Low bone turnover state in primary biliary cirrhosis. Нерatology 1987; 7: 137-42.

16 Mobarhan SA, Russell RM, Recker RR, Posner DB, Iber FL, Miller P. Metabolic bone disease in alcoholic cirrhosis: a comparison of the effect of vitamin $\mathrm{D}_{2}, 25$ hydroxyvitamin D, or supportive treatment. Hepatology 1984; 4: 266-73.

17 Review by an International Group. Acute and chronic hepatitis revisited. Lancet 1977; ii: 914-9.

18 Vedi S, Compston JE, Webb A, Tighe JR. Histomorphometric analysis of bone biopsies from the iliac crest of normal British subjects. Metab Bone Dis Rel Res 1982; 4: 231-6.

19 Payne RB, Little AJ, Williams RB, Milner JR. Interpretation of serum calcium in patients with abnormal serum proteins. $\mathrm{Br}$ Med J 1973; 4: 643-6.

20 Addison GM, Hales CN, Woodhead JS, O'Riordan JLH. Immunoradiometric assay of parathyroid hormone. J Endocrinol 1971; 49: 521-30.

21 Frost HM. A method of analysis of trabecular bone dynamics. In: Meunier PJ, ed. Bone histomorphometry. Second International Workshop. Toulouse, France: Societe de la Nouvelle Imprimerie Fournie, 1977: 445-76.

22 Parfitt AM, Mathews CHE, Villanueva AR, Kleerekoper M, Frame B, Rao DS. Relationships between surface, volume, and thickness of iliac trabecular bone in ageing and osteoporosis. J Clin Invest 1983; 72: 1396-409.

23 Meunier PJ, Courpron P, Edouard C, et al. Bone histomorphometry in osteoporosis. In: Barzel VS, ed. Osteoporosis II. New York: Grune and Stratton, 1979: 27-47.

24 Courpron $\mathrm{P}$, Lepine $\mathrm{P}$, Arlot $\mathrm{M}$, et al. Mechanisms underlying the reduction with age of the mean wall thickness of trabecular basic structure unit (BSU) in human iliac bone. In: Jee WSS, Parfitt AM, eds. Bone histomorphometry. Third International Workshop. Paris, France: Societe Nouvelle de Publications Medicales et Dentaires, 1981: 323-9.

25 Vedi S, Tighe JR, Compston JE. Measurement of total resorption surface in iliac crest trabecular bone in man. Metab Bone Dis Rel Res 1984; 5: 275-80.

26 Parfitt AM, Podenphant J, Villanueva AR, Frame B. Metabolic bone disease with and without osteomalacia after intestinal bypass surgery: a bone histomorphometric study. Bone 1985; 6: 211-20.

27 Kleerekoper M, Villanueva AR, Stanciu J, Rao DS, Parfitt AM. The role of three dimensional trabecular microstructure in the pathogenesis of vertebral compression fractures. Calcif Tissue Int 1985; 37: 594-7.

28 Dempster DW, Arlot MA, Meunier PJ. Mean wall thickness and formation periods of trabecular bone packets in corticosteroid-induced osteoporosis. Calcif Tissue Int 1983; 35: 410-7.

29 Rose JDR, Crawley EO, Evans WD, et al. Osteoporosis in chronic liver disease. Bone 1987; 8: 53. 